\title{
Numerical study and prediction of nuclear contaminant transport from Fukushima Daiichi nuclear power plant in the North Pacific Ocean
}

\author{
WANG Hui, WANG ZhaoYi ${ }^{*}$, ZHU XueMing, WANG DaKui \& LIU GuiMei \\ Key Laboratory of Research on Marine Hazards Forecasting, National Marine Environmental Forecasting Center, Beijing 100081, China
}

Received January 12, 2012; accepted March 23, 2012; published online May 30, 2012

\begin{abstract}
On March 11, 2011, a large earthquake and subsequent tsunami near the east coast of Japan destroyed the Fukushima Daiichi nuclear power plant (FD-NPP), causing a massive release of nuclear contaminants. In this paper, a Pacific basin-wide physical dispersion model is developed and used to investigate the transport of nuclear contaminants. The Pacific circulation model, based on the Regional Ocean Modeling System (ROMS), is forced with air-sea flux climatology derived from COADS (the Comprehensive Ocean-Atmosphere Data Set). It is shown that ocean current dominates nuclear contaminant transport. Following the Kuroshio Extension and North Pacific Current, nuclear contaminants at the surface will move eastward in the Pacific as far as $140^{\circ} \mathrm{W}$, thereafter dividing into two branches. For the south branch, nuclear contaminants will be transported westward by the equatorial current, and can reach the Philippines after 10 years' time. In contrast, the north branch will arrive at the American west coast and then migrate to the Bering Sea. At $200 \mathrm{~m}$ water depth, part of the nuclear materials will move southwestward along with deep ocean circulation, which could potentially reach the east coast of Taiwan. The other part will move to the west coast of America and separate into two branches. One will move northward along the west coast of Alaska, while the other will travel southward to the Hawaiian Islands. The transport of radiation contaminants below $500 \mathrm{~m}$ is slow, and will primarily remain in the central Pacific. The physical dispersion model results show that high concentrations of the radioactive isotope cesium-137 $\left({ }^{137} \mathrm{Cs}\right)$ will move eastward and reach the central Pacific and west coast of North America in two and eight years, respectively. The sea areas influenced by the nuclear contaminants continue to expand, while peak concentrations decrease in the North Pacific.
\end{abstract}

regional ocean model, nuclear contaminants, transport, prediction, ${ }^{137} \mathrm{Cs}$

Citation: Wang H, Wang Z Y, Zhu X M, et al. Numerical study and prediction of nuclear contaminant transport from Fukushima Daiichi nuclear power plant in the North Pacific Ocean. Chin Sci Bull, 2012, 57: 3518-3524, doi: 10.1007/s11434-012-5171-6

At 05:46 UTC on March 11, 2011, an enormous M9.0 earthquake occurred $\sim 130 \mathrm{~km}$ off the Pacific coast of the Japanese main island of Honshu, at $38.3^{\circ} \mathrm{N}, 142.4^{\circ} \mathrm{E}$. This was followed by a large tsunami (USGS, 2011: http://earthquake. usgs.gov/earthquakes/eqinthenews/2011/usc0001xgp/). Large amounts of radionuclides were emitted into the atmosphere and ocean from the Fukushima Daiichi Nuclear Power Plant (FD-NPP) as a result of a reactor accident caused by the Tohoku earthquake and tsunami [1,2]. Measurement data published by the Japanese Ministry of Education, Culture, Sports, Science and Technology (MEXT, 2011: http://

*Corresponding author (email: wangzy@nmefc.gov.cn) radioactivity.mext.go.jp/en/1270/2011/06/13047970616e.pdf) and others $[1,3]$ show that emissions from FD-NPP produced strongly elevated levels of radioactivity in Fukushima Prefecture and other parts of Japan. Enhanced concentrations of airborne radionuclides were measured at many locations all over the Northern Hemisphere [4,5].

As radioactive material tend to be transported and diffused following atmospheric and oceanic motions, it is a key scientific issue to track the transport of nuclear contaminants. The leaked nuclear material is transported via three channels - a fast channel by atmospheric circulation, a slow channel by ocean circulation, and a biological channel which includes human activities [6]. The atmospheric 
channel is so fast that nuclear material will be diluted and deposited over land and ocean within 3-4 months. The ocean channel is very slow, and it takes several years for the contaminants to be significantly transported. Transport through biological activity is insignificant compared to those from atmospheric and oceanic circulations.

For this nuclear leakage, observations and numerical simulations have been made to study the diffusion and deposition of radioactive isotopes in atmospheric aerosol. Special attention has been paid to the deposition rates of iodine-131 ( $\left.{ }^{131} \mathrm{I}\right)$, xenon-133 $\left({ }^{133} \mathrm{Xe}\right)$ and cesium-137 $\left({ }^{137} \mathrm{Cs}\right)$ [7-9]. It was shown that $~ 83 \%$ of ${ }^{131}$ I and $\sim 78 \%$ of ${ }^{137} \mathrm{Cs}$ has been deposited in the ocean [9]. As a result, the role of ocean transport is crucial in evaluating the potential long-term influence of nuclear contaminants.

In practice, it is difficult to study the transport of nuclear contaminants using field observations, which are expensive and have limited spatial and temporal resolution. Numerical models have been identified by the oceanographic community as economic and successful tools. The Pacific circulation pattern has been extensively explored on a basin scale [10-13]. For this leakage incident in Japan, several numerical studies have been conducted to predict the fate of radioactive contaminants in the ocean. These include studies by the Japan Agency for Marine-Earth Science and Technology (JAMSTEC, 2011: http://www.mext.go.jp/english/incident/ 1305758.htm) and Japan Atomic Energy Agency (JAEA, 2011: http://www.mext.go.jp/english/incident/1305758.htm). In addition, Qiao et al. [6] and Tsumune et al. [14] both performed a short-term numerical simulation. However, little work has been done regarding the transport and dispersion of nuclear contaminants on medium-term or longterm timescales.

In this paper, a Pacific basin-wide physical dispersion model is developed and used to investigate the transport of nuclear contaminants. The Pacific circulation model, based on the Regional Ocean Modeling System (ROMS) at resolution $1 / 8^{\circ} \times 1 / 8^{\circ}$, used $1 / 4^{\circ}$ gridded temperature and salinity climatology from GDEM (Generalized Digital Environment Model) as background field and forced with air-sea flux climatology derived from COADS (Comprehensive OceanAtmosphere Data Set). The model is then used to simulate and predict the transport of nuclear substances at the surface and ocean depths. Furthermore, the circulation model is coupled with a dispersion model to predict the dispersive trend of radioactive concentration.

\section{Numerical models}

We used the ROMS model [15] to simulate the behavior of radioactive pollutants released from FD-NPP. The ROMS is a free-surface, primitive equation ocean circulation model formulated using terrain-following coordinates. Our simulation domain covered the equator and northern Pacific Ocean $\left(15^{\circ} \mathrm{S}-61^{\circ} \mathrm{N}, 98^{\circ} \mathrm{E}-70^{\circ} \mathrm{W}\right)$. Because the model horizontal resolution had significant effects on the simulation of ocean circulation [16] and the low-resolution ocean model could only reveal basic characteristics of the research area [17], a high-resolution model was used to improve ocean model performance. The horizontal resolution was $1 / 8^{\circ}$ in both zonal and meridional directions, with 633 meshes in the zonal direction and 1545 in the meridional direction. The vertical resolution of the $\sigma$ coordinate was 22 layers. The ocean bottom was set at $7500 \mathrm{~m}$ depth to keep the pattern stable.

The bathymetry used here was derived from GEBCO (General Bathymetric Chart of the Oceans), a global 30 arc-second gridded bathymetry, which was supplied by the Intergovernmental Oceanographic Commission and International Hydrographic Organization. To reduce the influence of the seamount on model stability, the bathymetry was smoothed appropriately. At the surface, the model was forced by wind stress, heat fluxes and freshwater fluxes obtained from COADS. Initial conditions of temperature and salinity were derived from the monthly mean data climatology of SODA (Simple Ocean Data Assimilation), and initial conditions of horizontal current velocity and sea surface height were set to zero. Considering the effects of an open boundary on simulation [18], southern, western and northern boundaries were set as open boundaries, for which water level and velocity were also obtained from SODA. The internal model time step was $1200 \mathrm{~s}$ and the external model time step was $40 \mathrm{~s}$. Model spun-up for 11 years to reach a statistical equilibrium. Thereafter, tracers were released and the model was integrated for another 10 years.

\section{Validation}

We analyzed several important physical variables, such as sea surface temperature (SST), sea surface height (SSH) and sea surface currents, to evaluate simulation results for the North Pacific Ocean. Considering the hysteresis effect of oceanic conditions due to thermal inertia of the ocean, we compared the monthly mean simulation results with observations from WOA09 (World Ocean Atlas 2009), SODA and AVISO (Archiving, Validation and Interpretation of Satellite Oceanographic Data) from February and August. WOA09 was downloaded from the National Oceanic and Atmospheric Administration (NOAA: http://www.nodc. noaa.gov/oc5/WOA09/pr_woa09.html) at resolution $1.0^{\circ} \times$ $1.0^{\circ}$. SODA was derived from monthly mean data (http://dsrs. atmos.umd.edu) and horizontal resolution was $0.5^{\circ} \times 0.5^{\circ}$. AVISO, with meridional resolution $1 / 3^{\circ}$ and zonal resolution varying from $1 / 2^{\circ}-1 / 3^{\circ}$, was from monthly mean data over 1992-2010 (http://www.aviso.oceanobs.com).

\subsection{Sea surface temperature}

Figure 1 shows monthly mean SST climatology in February and August, from simulation and WOA09. The simulated 
SST (Figure 1(a),(b)) is consistent with that derived from WOA09 (Figure 1(c),(d)). In particular, there is a strong zonal temperature gradient along the tropical equator, with a high-temperature water body associated with the so-called "warm pool" in the western equatorial Pacific, and a regime of low temperature associated with the so-called "cold tongue" in the eastern equatorial Pacific. In subtropical basins, temperature is generally high near the western boundary and low in the eastern basin. In subpolar basins, the zonal temperature gradient reverses sign, with high temperature in the eastern basin and low temperature in the western basin. In addition, SST is reduced in the poleward direction, with high temperature in the equatorial Pacific and low temperature in the polar Pacific. Simulated SST is higher in February and lower in August, compared to WOA09 (Figure 1(c),(d)). SST is generally similar to the WOA09 in subtropical basins, high in February and low in August to the north of $40^{\circ} \mathrm{N}$. The ocean model at high spatial resolution can reasonably simulate the distribution of the warm pool and cold tongue. Nevertheless, simulation error to the north of $40^{\circ} \mathrm{N}$ may result from COADS net heat flux, which is strong in winter and weak in summer.

Two statistical methods [19] as shown in eqs. (1) and (2) are used to compare the difference between model results (ROMS) and WOA09 data.

$$
\begin{gathered}
\mathrm{ME}=\bar{Y}-\bar{X}, \\
\operatorname{RMS}=\left[\frac{1}{n} \sum_{i=1}^{n}\left(Y_{i}-X_{i}\right)^{2}\right]^{1 / 2},
\end{gathered}
$$

where ME is the mean errors, RMS is root mean square deviation, $i$ represents the month, and $n=12$.

The results show that the simulated SST is lower than that from SODA. ME values north of $45^{\circ} \mathrm{N}$ are mainly negative in February, with maximum deviation about $-1^{\circ} \mathrm{C}$, and positive in August, with maximum deviation about $1.5^{\circ} \mathrm{C}$. Nevertheless, ME values are all low in the equatorial Pacific (region between $15^{\circ} \mathrm{S}$ and $40^{\circ} \mathrm{N}$ ). ME obtained from the annual mean SST is lower in the internal basin than in the area near the shore, with an annual mean $\mathrm{ME}$ of $\sim 0.04^{\circ} \mathrm{C}$ in the North Pacific. RMS is lower in winter than in summer, with an annual mean of $\sim 0.53^{\circ} \mathrm{C}$, similar to $\mathrm{ME}$.

\subsection{Sea surface height}

The distribution of simulated SSH is shown in Figure 2(a),(b). By comparing the simulation results with SODA (Figure 2(c),(d)) and previous studies [11,12], we find that the model can capture the main SSH pattern. In the equatorial region and subtropical basins, SSH is generally high in the western basin and low near the eastern boundary. In subpolar basins, SSH declines from east to west. Generally speaking, geopotential in the poleward direction reveals a high-low-high-low orientation of the trough-ridge system. That is, equatorial trough, equatorial ridge, north equatorial countercurrent trough, North Pacific ridge, and subpolar trough.

By comparison with SSH from SODA, the simulation results reasonably depict the trough-ridge system and low-high distribution over the North Pacific. However, there are always errors and biases resulting from this comparison, such as errors $(\sim 0.1 \mathrm{~m})$ in the area north of $45^{\circ} \mathrm{N}$ and on two sides of the Kuroshio and Kuroshio Extension, which are probably related to the model resolution.

\subsection{Sea surface currents}

Figure 3 shows monthly mean sea surface currents obtained from simulation and AVISO for February and August. As the figure shows, several important current systems and
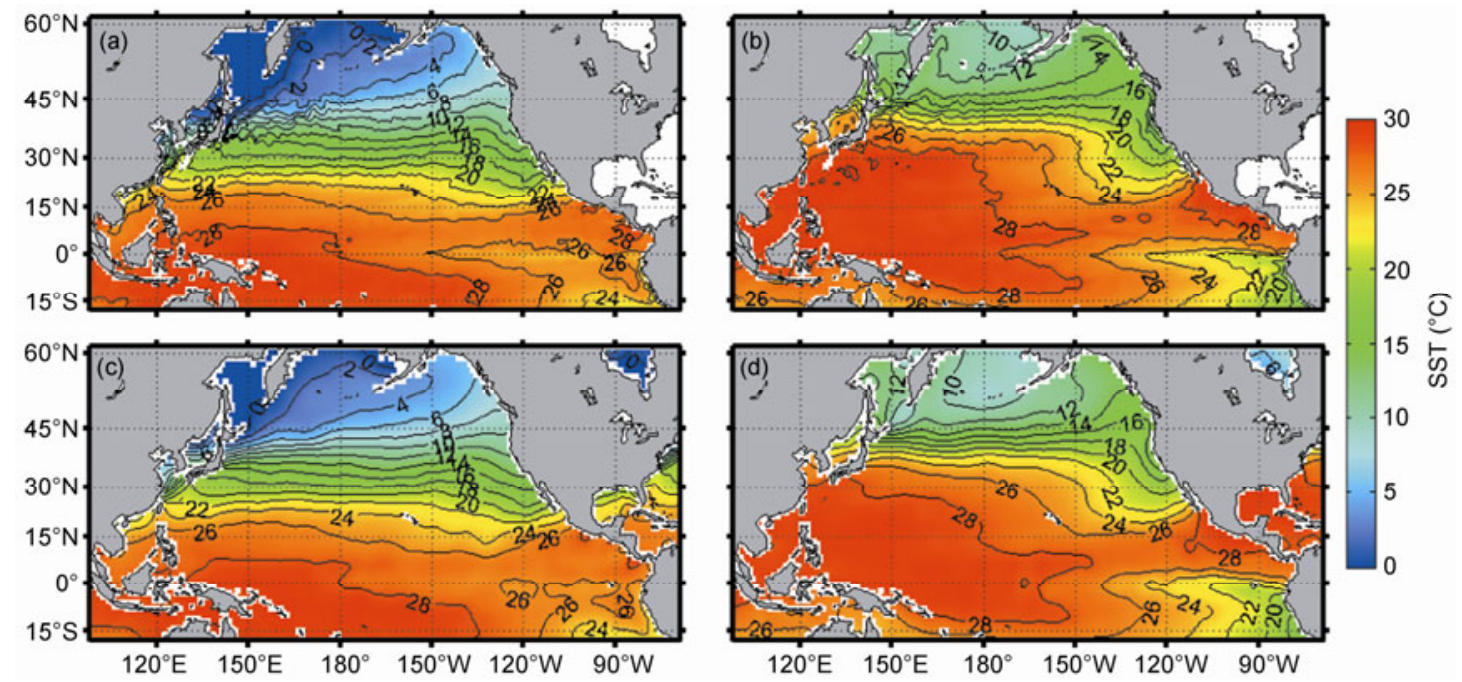

Figure 1 SST monthly climatology from model results and WOA09 data. (a) February from model; (b) August from model; (c) February from WOA09; (d) August from WOA09. 

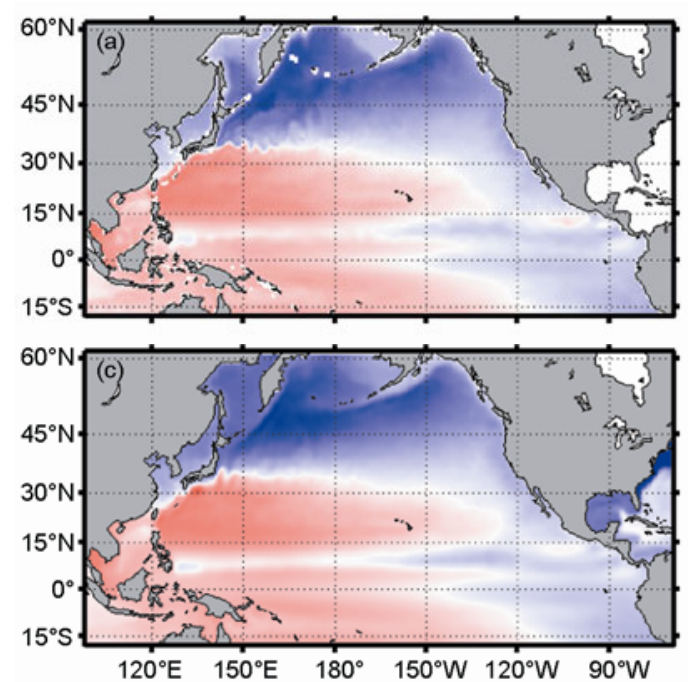

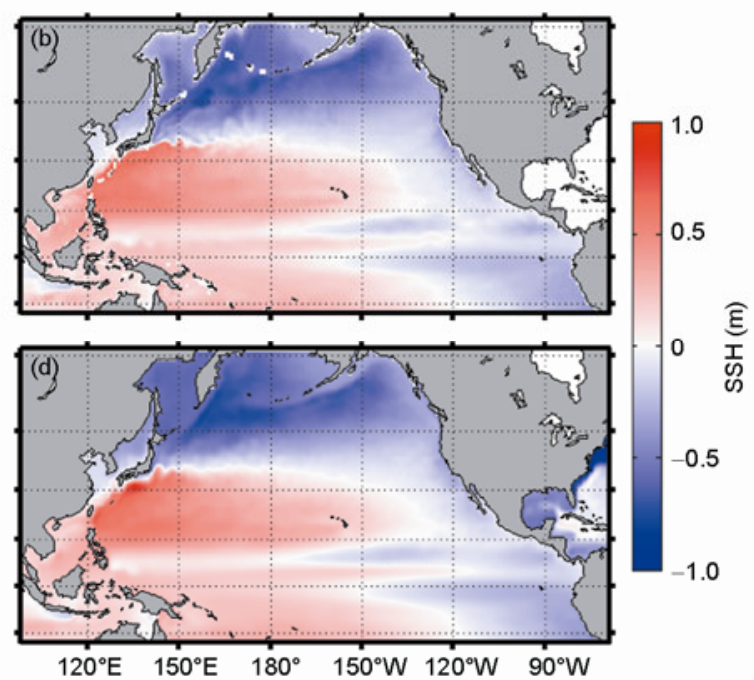

ह
ज
ल

Figure 2 SSH monthly climatology from model results and SODA data. (a) February from model; (b) August from model; (c) February from SODA; (d) August from SODA.
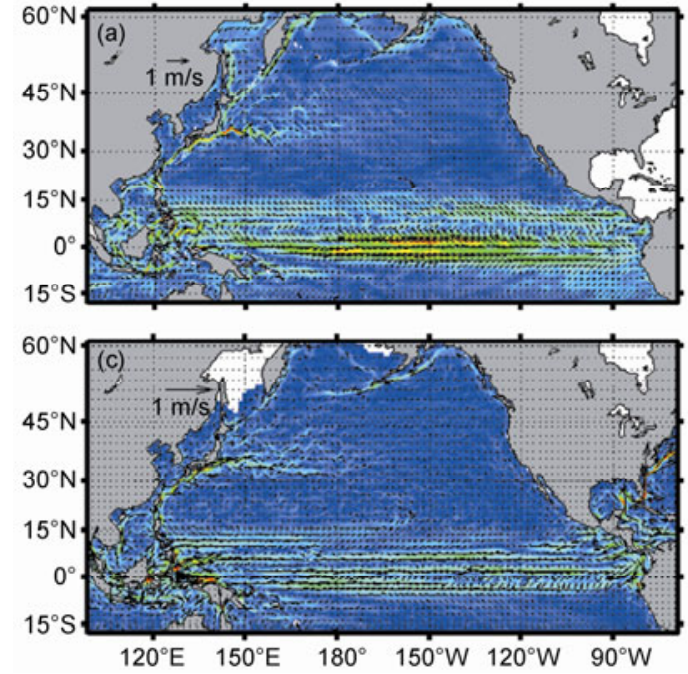

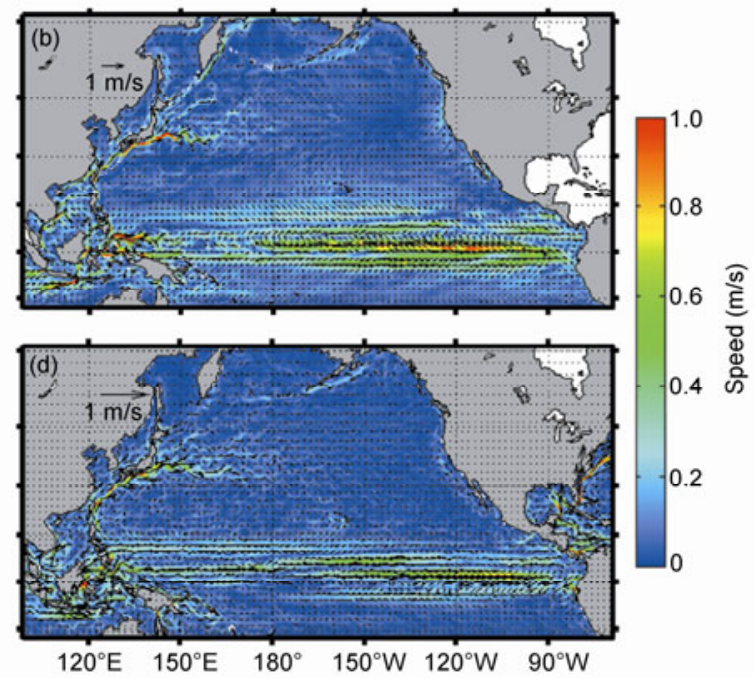

Figure 3 Monthly climatology of currents from model results and AVISO data. (a) February from model; (b) August from model; (c) February from AVISO; (d) August from AVISO.

vortexes in the North Pacific are well simulated, such as the Kuroshio, North Equatorial Current (NEC) and North Equatorial Countercurrent (NECC). Simulation results show that there is a North Pacific subtropical gyre that is anticyclonic (clockwise in the Northern Hemisphere), like all subtropical gyres. The NEC splits around $12^{\circ} \mathrm{N}$ into northward and southward boundary currents, i.e. the Kuroshio and Mindanao Currents, respectively. The Kuroshio enters (leaves) the South China Sea through the southern (northern) portion of the Luzon Strait, and thereafter flows northward along the east coast of Taiwan. After leaving Taiwan, it turns northeast along the edge of the East China Sea, until eventually turning east near Kyushu Island. After leaving the western boundary, the Kuroshio passes eastward through the Tokara Strait, tracks further east and roughly parallels the south coast of Japan. It enters the open Pacific at Boso Peninsula, after intersecting the Oyashio. Since when this current begins losing energy, it splits to form the North Pacific Current. The simulation is consistent with previous studies $[11-13,20]$. By comparison with the geostrophic flow from AVISO, the Kuroshio and Kuroshio Extension is well simulated, although simulated equatorial currents are stronger than those from AVISO.

As shown in the above analysis, simulated SST, SSH and surface currents are in good agreement with oceanic data climatology. This means that the model is well configured, and can be used to simulate the transport of nuclear contaminants in the oceanic channel. 


\section{Prediction}

Based on the circulation model, we can trace the spread of nuclear contaminants from March 11 of the 11th model year.

\subsection{Transport channel of low potential vorticity water}

The central North Pacific Ocean $\left(30^{\circ}\right.$ to $35^{\circ} \mathrm{N}, 150^{\circ}$ to $170^{\circ} \mathrm{E}$ ) is one of the main sources for low potential vorticity water in the Kuroshio-Oyashio Extensions. Based on previous research, there are such waters in North Pacific regions with density between $25.4 \sigma_{\theta}$ and $25.8 \sigma_{\theta}$ [21,22]. Figure 4 shows simulated average flow climatology on the $25.6 \sigma_{\theta}$ isopycnal surface in March. A transport channel of low potential vorticity water (Figure 4, black line) is determined by the streamline. Colors in the channel denote the mean circulation, with current speeds $\sim 0.02 \mathrm{~m} / \mathrm{s}$. Therefore, it takes approximately 12 years for the low potential vorticity water to transport from the central North Pacific to the east coast of Taiwan, following the subtropical gyre circulation. This is supported by previous studies [23]. Consequently, if the nuclear material is subducted in low potential vorticity waters, nuclear contaminants would affect the oceanic area east of Taiwan in 12 years.

\subsection{Prediction of ocean transport path}

On the basis of the ROMS circulation model, the first experiment is designed to simulate the spread of nuclear contaminants. This experiment is made under the assumption that nuclear contaminants would be transported and diffused along ocean currents without sinking or radioactivity. The release of 160 nuclear particles is assumed, at each level of sea surface, 200, 500, and $1000 \mathrm{~m}$ depths near Fukushima.
Another 60 particles were released in every layer near the Kuroshio pathway, as a comparison experiment. All particles are transported as 3D-Lagrangian drifters. Thereafter, spreading paths of the released nuclear contaminants are integrated for 10 years.

Figure 5(a) presents simulation results for the surface particles, in which red and blue lines denote the spread of particles near Fukushima and the Kuroshio pathway, respectively. Following the Kuroshio Extension and North Pacific Current, radioactive contamination at the surface will move eastward in the Pacific as far as $140^{\circ} \mathrm{W}$, dividing into two branches thereafter. For the south branch, nuclear contaminants will turn south between $170^{\circ}$ and $130^{\circ} \mathrm{W}$, and be transported west by the equatorial currents thereafter; they can reach the Philippines and South China Sea after 10 years of travel. In contrast, the north branch will arrive at the American western coast and then transport to the Bering Sea. At $200 \mathrm{~m}$ water depth (Figure 5(b)), part of the radioactive materials will move southwest along with deep ocean circulation, potentially reaching the east coast of Taiwan. The other part will transport to the west coast of North America and separate into two branches. One will move north along the west coast of Alaska, while the other will

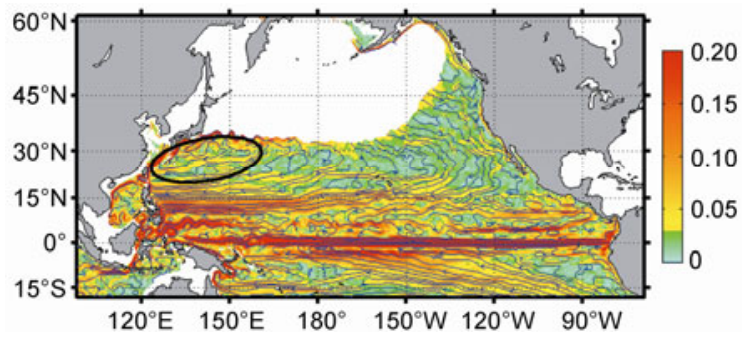

Figure 4 Positions of the channel (black line), plus climatological average flow on the $25.6 \sigma_{\theta}$ isopycnal surface (in March) $(\mathrm{m} / \mathrm{s})$.
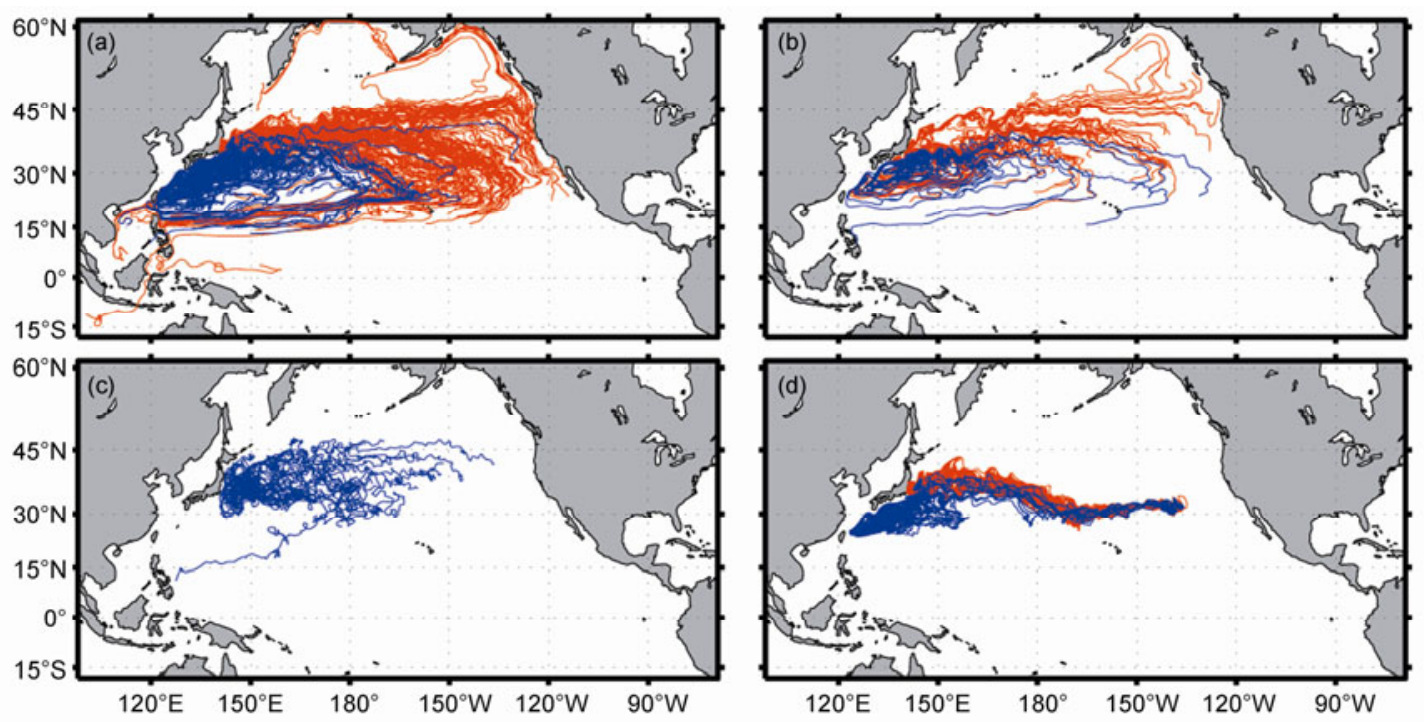

Figure 5 Horizontal trajectory of 3D-Lagrangrian particles. (a) Surface; (b) 200 m; (c) Argos trajectory; (d) trajectory particles fixed on surface. Red lines represent particles near Fukushima, blue lines particles near the Kuroshio pathway. 
travel south toward the Hawaiian Islands. The transport of radiation contaminants below $500 \mathrm{~m}$ is slow, and will largely remain within the central North Pacific. Figure 5(c) shows 43 Argos track paths between 1999 and 2010 near Fukushima (http://www.nodc.noaa.gov/argo/data/). Tracks of the drifters would mainly be transported eastward, similar to the 3D-Lagrangian simulation results (Figure 5(a),(b)). However, the Argos tracks would move along at relatively slow speeds. Argos tracks make vertical movement through automatic control with maximum depth $2000 \mathrm{~m}$, where current speeds are slow. This may be the reason for biases between Argos and simulation results.

Based on the above experiments, another experiment was designed to simulate the spread of nuclear radiation without consideration of the effect of vertical motion in the seawater. All particles move only with ocean currents in the horizontal direction for 10 years. Figure 5(d) shows simulation results from this experiment. Red and blue lines denote paths of nuclear particles after initial leakage, near Fukushima and the Kuroshio, respectively. The experiment without vertical motion shows that nuclear particles would gather near $\left(30^{\circ} \mathrm{N}, 135^{\circ} \mathrm{W}\right)$ in 10 years.

The two idealized experiments show very different results. The results by 3D-Lagrangrian trajectory method show more reasonable than those by the $2 \mathrm{D}$ method, suggesting that the 3D-Lagrangrian trajectory method play a better role in tracing leaked nuclear contaminants in the ocean.

\subsection{Prediction of nuclear contaminants}

The radioactive isotope ${ }^{137} \mathrm{Cs}$, with a half-life of 30.1 years, can negatively affect human life for decades, so the transport and diffusion process of ${ }^{137} \mathrm{Cs}$ should raise concern. On the basis of the ROMS circulation model, the evolution of ${ }^{137} \mathrm{Cs}$ is predicted with consideration of the decay and sinking processes of nuclear contaminants. The ${ }^{137} \mathrm{Cs}$ concentration decreases by radioactive decay with a half-life of 30 years, and by sedimentation at an assumed rate of $5 \mathrm{~m} / \mathrm{d}$. According to Tsumune et al. [14], direct release from the site contributed more to the measured ${ }^{137} \mathrm{Cs}$ concentration than atmospheric deposition. Therefore, an emission source was set in the area near Fukushima in our prediction, which excluded atmospheric sedimentation. Given uncertainty of the volume released into the ocean, one source of leaked nuclear materials was idealized at a unit per second in the ocean model, and would be automatically shut off one month later. The forecast of the ${ }^{137} \mathrm{Cs}$ distribution trend is shown in Figure 6. Because of the lack of space, only the distributions of ${ }^{137} \mathrm{Cs}$ in the 2 nd and 8 th year are shown.

It is shown that nuclear contaminants will diffuse eastward along with the ocean surface current (Kuroshio Extension) after leakage. After the source is shut off, nuclear contaminants would distribute on both sides of the Kuroshio Extension, because of the invasion of this extension. As

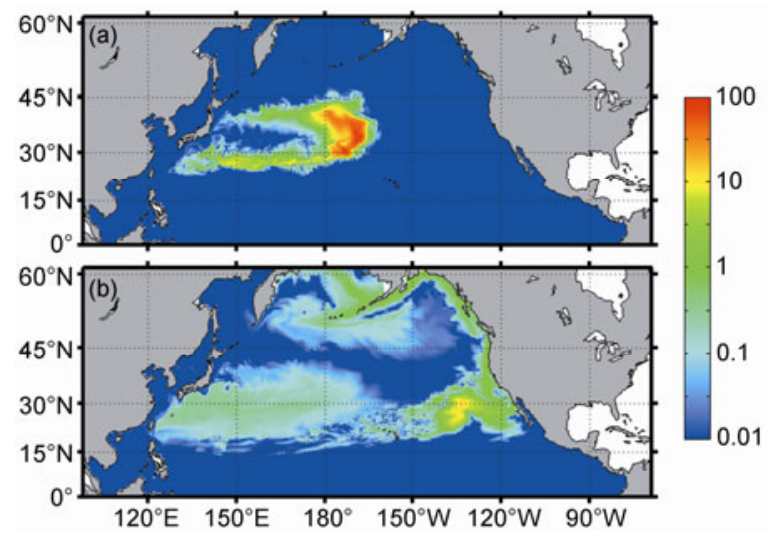

Figure 6 Model predictions of Cs-137 surface concentration. (a) 2nd year; (b) 8 th year.

shown in Figure 6(a), portions of low ${ }^{137} \mathrm{Cs}$ concentration distribute on the southern and northern sides of the Kuroshio Extension in two years, while high concentrations of radioactive ${ }^{137} \mathrm{Cs}$ isotopes reach the central Pacific basin. In addition, there is a small amount of ${ }^{137} \mathrm{Cs}$ diffused southwestward, along with ocean currents. Subsequently, contaminants on the northern side of the Kuroshio Extension diffuse northeastward with the North Pacific Current, and approach the American West Coast in five years. For the south branch, ${ }^{137} \mathrm{Cs}$ will be transported southwestward. In eight years, ocean areas influenced by the radioactive contaminants continue to expand, while concentrations decrease further east of the Kuroshio pathway. After reaching the west coast of North America, ${ }^{137}$ Cs will be transported southward and northward by coastal currents, affecting that entire coast, including the Bering Sea, but at low concentration. The peak concentration is located east of the Hawaiian Islands and decreases (Figure 6(b)). The entire North Pacific Ocean north of $15^{\circ} \mathrm{N}$ will be affected by nuclear contaminants in 10 years. Radioactive pollutants could also influence the China seas, but at extremely low concentration.

\section{Conclusion}

The M9.0 earthquake and massive tsunami of 11 March 2011 seriously damaged FD-NPP in Japan, causing a nuclear crisis. ROMS model was used to make a 10-year prediction of the transport of leaked nuclear radiation and change of ${ }^{137} \mathrm{Cs}$ concentration, and to analyze the low potential vorticity water channel at the $25.6 \sigma_{\theta}$ isopycnal. The main conclusions are as follows: (1) Nuclear contaminants subducted in low potential vorticity waters will affect the eastern area of Taiwan in 12 years. (2) Nuclear contaminants at the surface will move eastward in the Pacific as far as $140^{\circ} \mathrm{W}$, dividing into two branches thereafter. For the south branch, nuclear contaminants will be transported west by the equator currents, reaching the Philippines after 10 years' time. In contrast, the north branch will arrive at the Ameri- 
can West Coast and then transport to the Bering Sea. At 200 $\mathrm{m}$ water depth, part of the radioactive materials will move southwest along with deep ocean circulation, which could potentially reach the east coast of Taiwan. The other part will transport to the west coast of America and separate into two branches. One will move north along the west coast of Alaska, while the other will travel south toward the Hawaiian Islands. The transport of radiation contaminants below $500 \mathrm{~m}$ is slow, and will largely remain within the central Pacific in 10 years. (3) The peak concentration of ${ }^{137} \mathrm{Cs}$ will move eastward and approach the central North Pacific in two years. The high concentration of ${ }^{137} \mathrm{Cs}$ radioactive isotope will reach the Hawaiian Islands and approach the west coast of North America. In addition, the low concentrations of ${ }^{137} \mathrm{Cs}$ could affect the oceanic area east of Taiwan in five years. The location of peak concentration, east of the Hawaiian Islands, will not change in eight years, but will be a decreasing concentration. The entire North Pacific Ocean north of $15^{\circ} \mathrm{N}$ will be affected by nuclear contaminants in 10 years. Radioactive pollutants will also influence the China seas, but at low concentration.

This work was supported by the Major State Basic Research Development Program of China (2011CB403600) and the National Natural Science Foundation of China (40531006, 41076011 and 41106024).

1 Chino M, Nakayama H, Nagai H, et al. Preliminary estimation of release amounts of ${ }^{131} \mathrm{I}$ and ${ }^{137} \mathrm{Cs}$ accidentally discharged from the Fukushima Daiichi nuclear power plant into the atmosphere. J Nucl Sci Technol, 2011, 48: 1129-1134

2 Butler D. Radioactivity spreads in Japan. Nature, 2011, 471: 555-556

3 Yasunari T J, Stohl A, Hayano R S, et al. Cesium-137 deposition and contamination of Japanese soils due to the Fukushima nuclear accident. Proc Natl Acad Sci USA, 2011, 108: 19530-19534

4 Bowyer T W, Biegalski S R, Cooper M, et al. Elevated radioxenon detected remotely following the Fukushima nuclear accident. J Environ Radioact, 2011, 102: 681-687

5 Masson O, Baeza A, Bieringer J, et al. Tracking of airborne radionuclides from the damaged Fukushima Dai-lchi nuclear reactors by European Networks. Environ Sci Technol, 2011, 45: 7670-7677

6 Qiao F L, Wang G S, Zhao W, et al. Predicting the spread of nuclear radiation from the damaged Fukushima Nuclear Power Plant. Chin Sci Bull, 2011, 56: 1890-1896

7 Yutaka K. Monitoring of aerosols in Tsukuba after Fukushima Nuclear Power Plant incident in 2011. J Environ Radioact, 2011, doi: 10.1016/j.jenvrad.2011.10.011

8 Stohl A, Seibert P, Wotawa G, et al. Xenon-133 and caesium-137 releases intothe atmosphere from the Fukushima Dai-ichi nuclear power plant: determination of the source term, atmospheric dispersion, and deposition. Atmos Chem Phys, 2011,11: 28319-28394

9 Morino Y, Ohara T, Nishizawa M. Atmospheric behavior, deposition, and budget of radioactive materials from the Fukushima Daiichi nuclear power plant in March 2011. Geophys Res Lett, 2011, 38: L00G11

10 Fang G H, Wei Z X, Wang Y G, et al. An extended variable-grid global ocean circulation model and its preliminary results of the equatorial Pavific Circulation (in Chinese). Acta Oceanol Sin, 2004, 23: 23-30

11 Xu Y F, Li Y C, Zhao L, et al. A basin-wide ocean general circulation model of the Pacific Ocean and its simulation results (in Chinese). Chin J Atmos Sci, 2006, 30: 927-938

12 Mo $\mathrm{H}$ E, Yu Y Q, Liu H L, et al. Preliminary results from a high-resolution Pacific-Indian basin-wide ocean general circulation model (in Chinese). J Trop Ocean, 2009, 28: 56-65

13 Cai Y, Wang Z G. Simulation of Pacific Ocean Circulation based on global warming from 1960 to 1999. Mar Sci Bull, 2010, 12: 10-15

14 Tsumune D, Tsubono T, Aoyama M, et al. Distribution of oceanic Cs137 from the Fukushima Dai-ichi Nuclear Power Plant simulated numerically by a regional ocean model. J Environ Radioact, 2011, doi: 10.1016/j.jenvrad.2011.10.007

15 Malcolm J, Roberts A, Clayton M, et al. Impact of resolution on the Tropical Circulation in a matrix of coupled models. J Clim, 2009, 22: 2541-2556

16 Shchepetkin A F, McWilliams J C. The Regional Ocean Modeling System (ROMS): A split-explicit, free-surface, topography following coordinates oceanic model. Ocean Model, 2005, 9: 347-404

17 Gates W L, Mitchell J F B, Boer G J, et al. Climate modeling, climate prediction and model validation. In: Climate Change 1992. The Supplementary Report to the IPCC Scientific Assessment. Cambridge: Cambrige University Press, 1992. 101-134

18 Zhao L, Xu Y F. Effect of boundary condition on A basinwide scale ocean general circulation model for the North Pacific (in Chinese). Adv Mar Sci, 2006, 24: 292-300

19 Gao S, Lü X Q. Simulation of sea surface temperature of equatorial and North Pacific using a hybrid coordinate ocean model (in Chinese). Adv Mar Sci, 2007, 25: 257-267

20 Xia C S, Qiao F L, Zhang Q H, et al. Numerical modeling of the quasi-global ocean circulation base on POM. J Hydrodyn, 2004, 16: 537-543

21 Kobashi, Kawamura. Variation of sea surface height at periods of 65-220 days in the subtropical gyre of the North Pacific. J Geophys Res, 2001, 106: 817-831

22 Suga T, Kimio $\mathrm{H}$. The subtropical mode water circulation in the North Pacific. J Phys Oceanogr, 1995, 25: 958-970

23 Liu Q Y, Hu H B. A subsurface pathway for low potential vorticity transport from the central North Pacific toward Taiwan Island. Geophys Res Lett, 2007, 34: L12710

Open Access This article is distributed under the terms of the Creative Commons Attribution License which permits any use, distribution, and reproduction in any medium, provided the original author(s) and source are credited. 